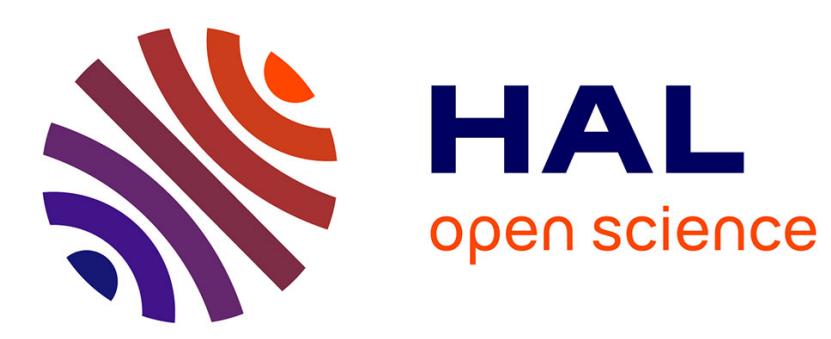

\title{
Design of a brushless DC permanent-magnet generator for use in micro-wind turbine applications
}

\author{
Andreea Laczko (zaharia), Stephane Brisset, Mircea Radulescu
}

\section{To cite this version:}

Andreea Laczko (zaharia), Stephane Brisset, Mircea Radulescu. Design of a brushless DC permanentmagnet generator for use in micro-wind turbine applications. International Journal of Applied Electromagnetics and Mechanics, 2018, 56, pp.3 - 15. 10.3233/JAE-172279 . hal-01913725

\section{HAL Id: hal-01913725 \\ https://hal.science/hal-01913725}

Submitted on 6 Nov 2018

HAL is a multi-disciplinary open access archive for the deposit and dissemination of scientific research documents, whether they are published or not. The documents may come from teaching and research institutions in France or abroad, or from public or private research centers.
L'archive ouverte pluridisciplinaire HAL, est destinée au dépôt et à la diffusion de documents scientifiques de niveau recherche, publiés ou non, émanant des établissements d'enseignement et de recherche français ou étrangers, des laboratoires publics ou privés. 


\title{
Design of a Brushless DC Permanent-Magnet Generator for Use in Micro-Wind Turbine Applications
}

\author{
Andreea LACZKO (ZAHARIA)***, Stéphane BRISSET** and Mircea RADULESCU* \\ *Technical University of Cluj-Napoca, Faculty of Electrical Engineering, Department of Electrical \\ Machines and Drives, RO-400027, Cluj-Napoca, Romania \\ E-mail: andreea.laczko@mae.utcluj.ro, mircea.radulescu@mae.utcluj.ro \\ ** Univ. Lille, Centrale Lille, Arts et Metiers ParisTech, HEI, EA 2697 - L2EP - Laboratoire \\ d'Electrotechnique et d'Electronique de Puissance, F-59000 Lille, France \\ E-mail: stephane.brisset@ centralelille.fr
}

\begin{abstract}
This paper deals with the optimal design of a direct-driven brushless DC permanent-magnet (BLDCPM) generator over a long-term wind speed cycle operation. Such a large wind speed profile causes long processing time in the search of the optimal solution, therefore a simplification method of the profile based on an original barycenter method is proposed and applied to the power losses computation of the wind energy system. As a result, the optimization methodology relies on two modeling levels different in simulation time and approach and is based on a constrained mono-objective problem with adequate optimization strategy and algorithm that aims at reducing the global system power losses for the given wind speed profile while finding the optimal geometrical and electrical features of the BLDCPM wind generator.
\end{abstract}

Keywords: barycenter method, brushless DC permanent-magnet generator, design, optimization, wind cycle.

\section{Introduction}

Brushless direct current (DC) permanent magnet machines have become widely used in various industrial applications due to the advantages that define them and their ease of control. The lack of brushes in their configuration yields several benefits for this topology as improved efficiency, better reliability, longer life with less maintenance, higher power density and higher torque to weight ratio [1], [2].

The optimal design of a brushless DC permanent magnet (BLDCPM) generator for the considered architecture of the wind energy conversion system to be studied in order to minimize a specific objective function, i.e. total power losses over one year wind-speed cycle operation, depends on the appropriate selection of the multiple design parameters. The structure presented in Fig. 1 can be considered as a good example of a complex wind energy conversion system (even if limited to the DC bus) as it incorporates subsystems belonging to different physical domains with strong interference between each other, imposing to consider the globalism of the system in the design process, rather than exploring them separately. Therefore, the approach based on design optimization is justified and even necessary for achieving optimal results in a short amount of time.

Due to the many operating points within the wind speed profile and because the optimization process requires many evaluations of the objective function, adapted models have to be considered in terms of results accuracy and simulation time. The most preferred is the one based on finite element analysis, because of its high precision. However, it is well known for its huge evaluation time making it a displeasing strategy to be considered in optimization. Nevertheless, it can be used outside the optimization loop as a validation model in order to refine the obtained results. But, when dealing with few initial specifications and many unknown parameters specific analytical and/or semi-analytical models are preferred over the numerical ones, as they perform much faster.

This paper describes the considered optimization methodology used in the search of the optimal design of a directdriven BLDCPM generator with trapezoidal induced electromotive force (back-EMF) voltages for use in microwind turbine applications. The optimization process is based on two modeling levels of different time scales and of different approaches, in order to calculate the generator's performances. As the optimization will be performed over a long term wind speed profile, adequate simplification method of the profile is proposed and applied to the power losses calculation of the overall wind energy system. In order to achieve feasible solution several constraints have to be analyzed on the input/outputs of the model, resulting in a constrained mono-objective optimization. Due to the wind speed cycle operation, suitable algorithm and optimization strategy are also considered in order to find the global optimum of the objective function and to reduce the probability of falling into a local minimum.

\section{Modeling description of the wind energy system components}

\subsection{Wind speed profile and wind turbine model}

The long-term wind speed profile considered is represented by the mean value taken over one hour of wind measurements, every hour for one year, resulting into 8759 operating points. A problem that can appear when 


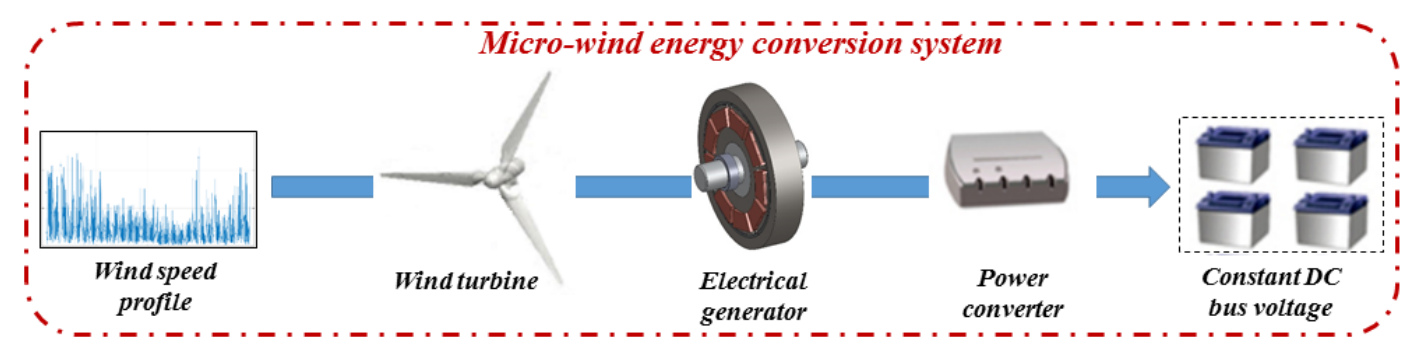

Fig. 1. Architecture of the wind energy conversion system under study

designing the generator over such a long term wind speed profile is linked to the direct-driven variable speed operation, meaning that the many fluctuations in the wind speed are visible in the power and frequency of the generator.

As the wind turbine power changes with the cube of the wind speed, its expression emphasizes the importance that the dynamic properties of the wind speed have upon the wind energy conversion system. Hence, the three-bladed horizontal axis wind turbine chosen for this study provides the assessment of the available power in the wind speed [3] as:

$$
P_{w t}=0.5 \rho_{\text {air }} \pi R_{w t}^{2} C_{p}(\lambda) v_{w}^{3}
$$

with $\rho$ air being the air density $\left(\mathrm{kg} / \mathrm{m}^{3}\right), R_{w t}$ denotes the radius of the turbine-rotor blades $(\mathrm{m}), \lambda$, the tip-speed coefficient, $v_{w}$, the wind speed $(\mathrm{m} / \mathrm{s})$, and $C_{p}$ the power coefficient of the turbine, which provides an idea about how many of the kinetic energy from the air mass can be converted into mechanical energy by the wind turbine. This coefficient can be calculated through interpolation based on the factors provided in [4].

\subsection{Simulation models of the generator-rectifier assembly}

Two simulation models have been developed to characterize the behavior of the wind energy conversion system. Both of them depend on the sizing characteristics [5] of the generator (Fig. 2a) that is determined beforehand and works as a background function for each of the simulation model during the optimization.

A) Analytical simulation model [6]: This model is based on the sizing characteristics of the generator, whereas its electromagnetic parameters are derived from the circuit equations of the machine by considering only the amplitude of the involved quantities. It is characterized as the fastest of the models, being very suited for the initial stage of design upon which the optimization could be performed. To be noted that no control is implemented for this model as the commutation of the phases is not explicitly taken into consideration.

B) Semi-analytical simulation model [6],[7]: This second model (Fig. 2b) is developed to take into account the switching pattern that depends on rotor angular position, the hysteresis current-control, as well as the commutation and conduction intervals of the controlled pulse width modulation (PWM) rectifier. It provides a better precision of the output solution than the analytical one, but it engages a long time for the simulation of all the points within the wind speed profile. In order to speed up its evaluation a wind speed cycle partition technique based on barycenter method is adapted to the maximum power point tracking (MPPT) operation area of the wind turbine and implemented in terms of wind energy system power losses. The adopted MPPT control strategy corresponds to an operation of the wind turbine at optimal power coefficient $\left(C_{p_{\text {_opt }}}\right)$ and optimal tip-speed ratio $\left(\lambda_{\text {opt }}\right)$ [7]. The barycenter method divides the wind speed profile into a chosen number of regions (Fig. 3a), each region (r) being represented by its barycenter and the necessary parameters (Fig. 3b) needed for the losses calculation. The required parameters are derived by assuming, depending on the corresponding power loss expression, the electromagnetic power of the BLDCPM generator proportional to the cube of the wind speed and the rotational angular speed, $\Omega$, linked to the wind speed through the equation of the tip-speed ratio. Accordingly, the electromagnetic torque of the generator is considered proportional to the square of the wind speed, being also expressed as a current dependent characteristic. An explicit description of the determination process of the power losses equations based on the barycenter method is reported in [6].

The expressions for these power losses are based on the equations provided in [4], [8], [9] and reformulated afterwards in connection to the barycenter method in order to calculate them for each region as follows:

$>$ Mechanical losses [4], [8] due to friction phenomena :

$$
P_{\text {mech }, r}=f_{w t} \Omega_{r}^{2} N_{r} \frac{\left\langle v_{w}^{2}\right\rangle_{r}}{\left\langle v_{w}\right\rangle_{r}^{2}}
$$

with $f_{w t}$ the friction coefficient (N.m/rad), $N_{r}$ the number of points in the region, $\Omega_{r}$ the corresponding rotational speed $(\mathrm{rad} / \mathrm{s})$ of the region in cause, and $\langle\cdot\rangle_{r}$ denotes the mean value in the region.

$>$ Copper losses [8] caused by the induced currents in the stator windings :

$$
P_{j, r}=3 R I_{R M S, r}^{2} N_{r} \frac{\left\langle v_{w}^{4}\right\rangle_{r}}{\left\langle v_{w}\right\rangle_{r}^{4}}
$$




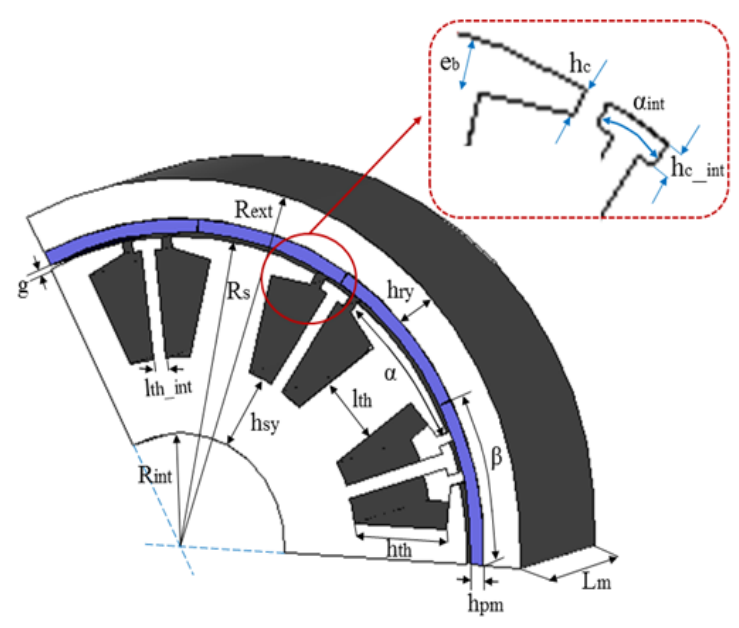

a)

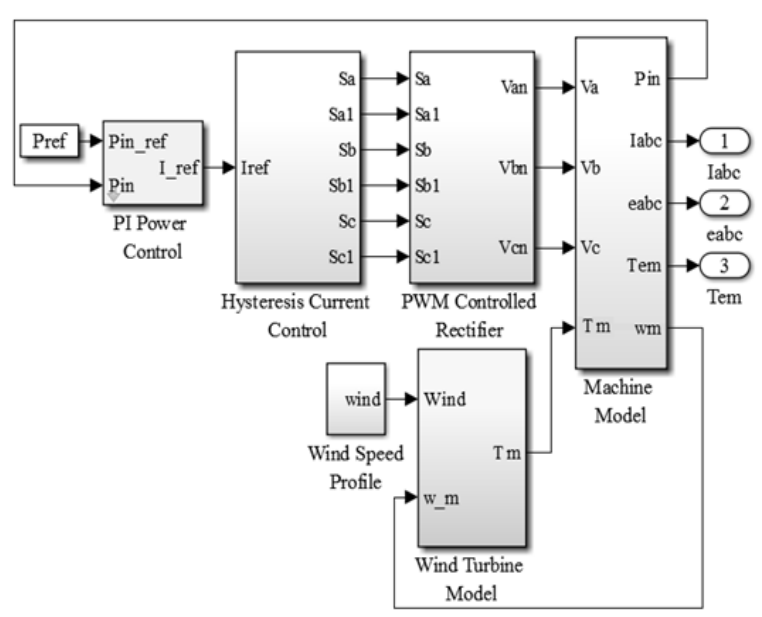

b)

Fig. 2. a) Geometric features of the BLDCPM generator and b) Semi-analytical simulation model implementation in MATLAB/Simulink environment

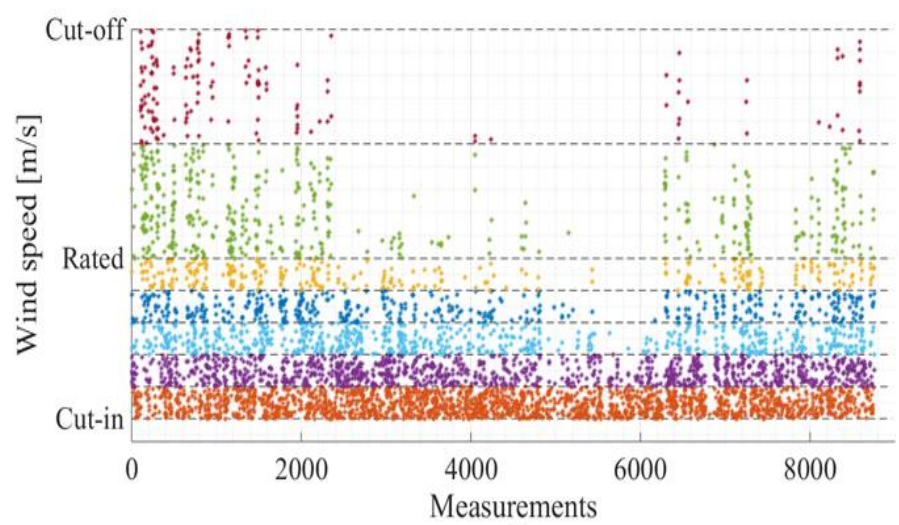

a)

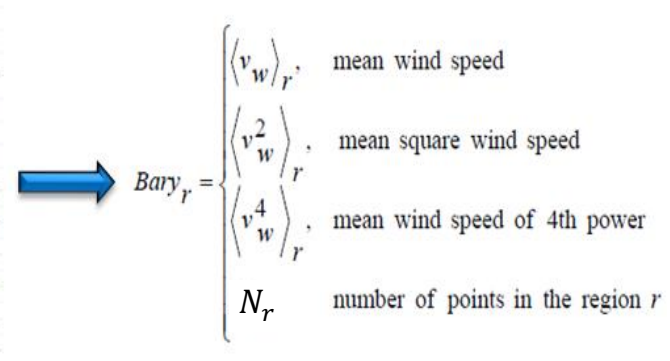

b)

Fig. 3. a) Wind speed cycle division into a chosen number of regions and b) barycenter method parameters

where $R$ represents the phase resistance (ohm) and $I_{R M S, r}$ the phase current (A) of the barycenter for the considered region.

$>$ Iron losses [8] based on the magnetic properties of the materials :

$$
\begin{gathered}
P_{F e_{-} h y s, r}=k_{\text {hys }} \frac{N_{p}}{2 \pi}\left(\hat{B}_{t h}^{\alpha}+\hat{B}_{s y}^{\alpha}\right) \Omega_{r} N_{r} \frac{\left\langle v_{w}\right\rangle_{r}}{\left\langle v_{w}\right\rangle_{r}} \\
P_{F e_{-} e d d y, r}=k_{\text {eddy }} \frac{N_{p}^{2}}{\pi^{3}}\left(\hat{B}_{t h}^{2}+2 \hat{B}_{s y}^{2}\right) \Omega_{r}^{2} N_{r} \frac{\left\langle v_{w}^{2}\right\rangle_{r}}{\left\langle v_{w}\right\rangle_{r}^{2}}
\end{gathered}
$$

where $k_{h y s}$ and $k_{e d d y}$ are hysteresis, respectively eddy current loss coefficients which can be calculated from manufacturer data, $N_{p}$ the pole pairs number and $\widehat{B}_{t h}$ and $\hat{B}_{s y}$ are the peak values of the stator tooth and yoke flux densities.

$>$ Conduction and switching losses [9] in the three-phase power converter based IGBT devices with anti-parallel diode units:

$$
\begin{gathered}
P_{\text {conduction_IGBT }, r}=6\left[\frac{1}{3} f_{\text {mod }}\left(\frac{V_{C E}-V_{C E 0}}{I_{n_{-} I G B T}}\right) I_{C_{-} R M S, r}^{2} N_{r} \frac{\left\langle v_{w}^{4}\right\rangle_{r}}{\left\langle v_{w}\right\rangle_{r}^{4}}+\frac{1}{3} f_{\text {mod }} V_{C E 0} I_{C_{-} R M S, r} N_{r} \frac{\left\langle v_{w}^{2}\right\rangle_{r}}{\left\langle v_{w}\right\rangle_{r}^{2}}\right] \\
P_{\text {Switching_IGBT }, r}=6\left[\frac{1}{3}\left(E_{\text {ON }}+E_{\text {OFF }}\right) \frac{V_{n}}{V_{C C(t e s t)} I_{C C(t e s t)}} I_{C_{-} p k, r} f_{S w} N_{r} \frac{\left\langle v_{w}^{2}\right\rangle_{r}}{\left\langle v_{w}\right\rangle_{r}^{2}}\right] \\
P_{\text {diode }, r}=6\left[\frac{1}{3}\left(1-f_{\text {mod }}\right) V_{F} I_{C_{-} R M S, r} N_{r} \frac{\left\langle v_{w}^{2}\right\rangle_{r}}{\left\langle v_{w}\right\rangle_{r}^{2}}\right]+6 V_{F} T_{\text {comm }} f_{\text {ele }} I_{F_{-} A V G, r} N_{r} \frac{\left\langle v_{w}^{2}\right\rangle_{r}}{\left\langle v_{w}\right\rangle_{r}^{2}} \\
I_{C_{-} R M S}=I_{R M S}, \quad, \quad I_{C_{-} p k}=I_{R M S}+10 \% I_{R M S}, \quad I_{F_{-} A V G}=I_{C_{-} p k} / 2
\end{gathered}
$$




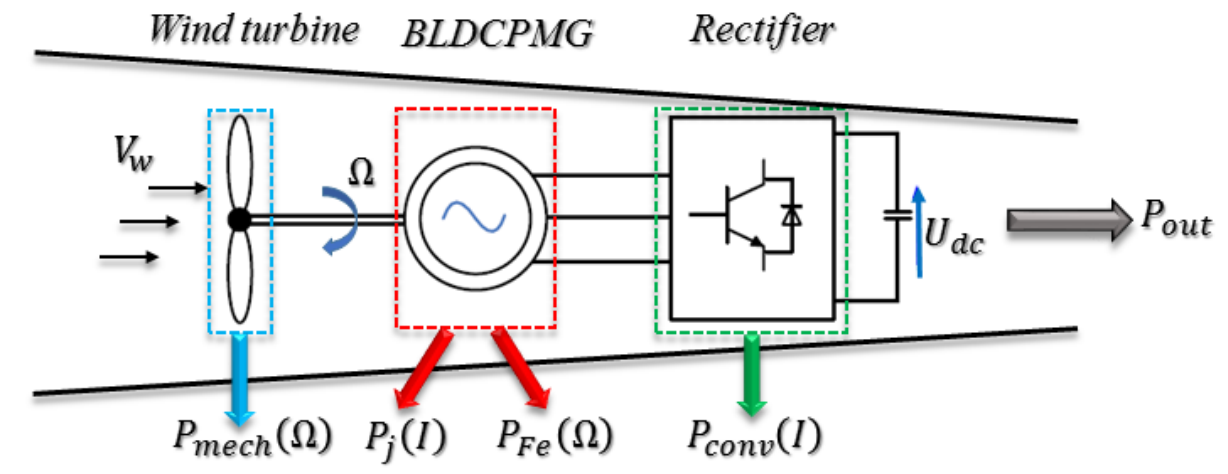

Fig. 4. Power flow in the wind energy conversion system

with $f_{\text {mod }}$ the modulation factor, $V_{C E}$ the collector-emitter voltage of the insulated gate bipolar transistor (IGBT) $(\mathrm{V}), V_{C E 0}$ is the ON-state, zero current collector-emitter voltage $(\mathrm{V})$ which can be obtained from the manufacturer datasheet, $I_{n_{-} I G B T}$ represents the nominal current of the transistors, $I_{C_{-} R M S}$ is the current during the $120^{\circ}$ switch conduction period, $E_{O N}$ and $E_{O F F}$ denote the turn-on and turn-off switching losses (J) of the transistors, $V_{C C(t e s t)}$ and $I_{C C(t e s t)}$ describe the test voltage $(\mathrm{V})$ and current $(\mathrm{A}), I_{C-p k}$ is calculated for a $110 \%$ overload of the generator winding current, $f_{s w}$ is the switching frequency $(\mathrm{Hz}), V_{F}$ the forward $\mathrm{ON}$ voltage in the diodes $(\mathrm{V}), T_{\text {comm }}$ and $f_{\text {ele }}$ express the phase commutation time (s) and the fundamental frequency of the machine (Hz), respectively and finally $I_{F_{-} A V G}$ is the average forward current of the diode during phase commutation.

\section{Optimization problem description}

\subsection{Mono-objective function}

The objective function proposed for resolution is represented by the minimization of the overall power losses $\left(P_{\text {total_loss }}\right)$ in the system, based on the power flow presented in Fig. 4, during one year wind speed cycle operation, which indirectly implies the maximization of the output useful power. Other possible objectives could be the manufacturing cost, the reliability of the system, the lifetime expectancy, etc. but the amount of renewable energy provided by the wind turbine is preferred as it is correlated with major environmental concerns such as energy depletion and climate change.

$$
O P_{1}=\min \left(P_{\text {total_loss }}\right)=\min \left(P_{\text {mech }_{-} t}+P_{j_{-} t}+P_{F e_{-} t}+P_{\text {conv } \_} t\right)
$$

\subsection{Design variables and constraints}

The continuous (c) and discrete (d) type variables of the wind energy system considered to be optimized are presented in Table 1, along with their associated variation domain. The performance operating points of the wind turbine, i.e. the cut-in, rated and cut-off wind speeds are also set as variables to be optimized in order to provide the optimal turbine power curve and consequently the nominal power of the generator. As they strongly influence the length of the wind profile to be considered in the calculation of the wind energy system power losses and due to the nature of the employed optimization algorithm, their range of definition is slightly narrowed so that the turbine to start its operation at a cut-in wind speed less than the average wind of the profile. The cut-off wind speed is chosen to prevent the forces acting on the turbine structure at high wind speeds to damage the rotor. Depending on the design cost of the wind turbine a lower value can be set for this parameter, however for this study its proposed definition domain was favored to assess the large amount of data within the wind speed profile.

The many design variables to be optimized may lead to non-feasible configurations as results of the optimization process. To resolve this difficulty several constraints were imposed on the:

- Useful (output) power at cut-in wind speed:

$$
P_{\text {out } \_ \text {vin }}>0[\mathrm{~W}]
$$

- Generator inner diameter:

$$
D_{\text {int }} \geq 80[\mathrm{~mm}]
$$

- Permanent magnet thickness:

$$
h_{p m} \leq 6[\mathrm{~mm}]
$$

- Maximum temperature of the copper windings:

$$
T_{C u, r} \leq 130\left[{ }^{\circ} \mathrm{C}\right]
$$

Table 1. Wind turbine system design variables 


\begin{tabular}{cccc}
\hline \hline Variable & Notation & Type & Definition domain \\
\hline \hline Cut-in wind speed $[\mathrm{m} / \mathrm{s}]$ & $v_{\text {in }}$ & $\mathrm{c}$ & {$[1 \div 4]$} \\
\hline Nominal wind speed $[\mathrm{m} / \mathrm{s}]$ & $v_{n}$ & $\mathrm{c}$ & {$[4 \div 20]$} \\
\hline Cut-off wind speed [m/s] & $v_{\max }$ & $\mathrm{c}$ & {$[20 \div 27]$} \\
\hline Number of pole pairs & $N_{p}$ & $\mathrm{~d}$ & $\{2, \ldots, 20\}$ \\
\hline Stator bore diameter [mm] & $D_{s}$ & $\mathrm{c}$ & {$[100 \div 500]$} \\
\hline Magnetic length [mm] & $L_{m}$ & $\mathrm{c}$ & {$[50 \div 500]$} \\
\hline Air gap thickness [mm] & $g$ & $\mathrm{c}$ & {$[0.5 \div 5]$} \\
\hline Ratio length rotor/stator & $r_{r s}$ & $\mathrm{c}$ & {$[1 \div 1.2]$} \\
\hline Peak magnetic induction in the airgap [T] & $\widehat{B}_{g}$ & $\mathrm{c}$ & {$[0.5 \div 1]$} \\
\hline Peak magnetic induction in the rotor yoke $[\mathrm{T}]$ & $\widehat{B}_{r y}$ & $\mathrm{c}$ & {$[0.6 \div 1.6]$} \\
\hline Peak magnetic induction in the stator yoke [T] & $\widehat{B}_{s y}$ & $\mathrm{c}$ & {$[0.6 \div 1.6]$} \\
\hline Peak magnetic induction in the stator teeth $[\mathrm{T}]$ & $\widehat{B}_{t h}$ & $\mathrm{c}$ & {$[0.6 \div 1.8]$} \\
\hline Current density [A/mm $\left.{ }^{2}\right]$ & $\delta_{d e n s}$ & $\mathrm{c}$ & {$[0.5 \div 8]$} \\
\hline Ratio DC voltage/EMF & $k_{v}$ & $\mathrm{c}$ & {$[0.5 \div 10]$} \\
\hline Commutation frequency [kHz] & $f_{s w}$ & $\mathrm{c}$ & {$[1 \div 30]$} \\
\hline DC bus voltage [V] & $V_{d c}$ & $\mathrm{c}$ & {$[48 \div 300]$} \\
\hline \hline
\end{tabular}

Table 2. Genetic algorithm control parameters

\begin{tabular}{cc}
\hline \hline Population size & 500 \\
\hline Number of generations & $100 *$ number of design variables \\
\hline Crossover Probability & 0.8 \\
\hline Mutation Rate & $1 /$ number of design variables \\
\hline \hline
\end{tabular}

- Maximum current in the phase windings to avoid magnets demagnetization:

$$
I_{R M S, r} \leq I_{\text {demag }} / 3
$$

- $\quad$ Rising time of the phase current:

$$
\text { time_I } I_{R M S, r} \leq \frac{1}{30 f_{\text {ele }}}[\mathrm{s}]
$$

- Relative hysteresis band-width of stator current:

$$
\frac{\Delta i_{r}}{I_{R M S, r}} \leq 0.1
$$

- Generator total mass:

$$
M_{\text {gen_t }} \leq 20[\mathrm{~kg}]
$$

- Generator efficiency over the long-term wind cycle, obtained as the ratio between the total output power $\left(\sum_{i=1}^{N}\left\langle P_{\text {out_gen }}\right\rangle_{i}\right)$ of the generator and the total input power given by the wind turbine $\left(\sum_{i=1}^{N}\left\langle P_{\text {in_wt }}\right\rangle_{i}\right)$, with $N$ being the number of wind speeds within the considered wind profile:

$$
\eta_{\text {gen_cycle }} \geq 0.9
$$

Equations (14)-(17) are set of constraints that apply to all regions.

The above problem formulation becomes a constrained mono-objective optimization that is solved by using a stochastic method, in particular the genetic algorithm (GA) [10] from the MATLAB® environment to find the geometrical and electrical parameters that satisfy the problem constraints while performing the minimization of the power losses of the wind energy system over one year wind speed profile. The considered control parameters of the genetic algorithm are those listed in Table 2.

\section{Optimization methodology and results}

\subsection{Single-level optimization approach}

The first attempt is to perform the optimization upon the analytical simulation model based on few initial data and specifications, so that a first design that respects all the constraints could be generated. The workflow of the global design optimization process for the single level approach is depicted in Fig. 5.

After 11 minutes and 526,001 model evaluations, the optimization upon the analytical model is finished and the optimum design variables are further used for verifying the obtained results by evaluating with them the semianalytical model over complete wind cycle operation and also the semi-analytical model associated to the 


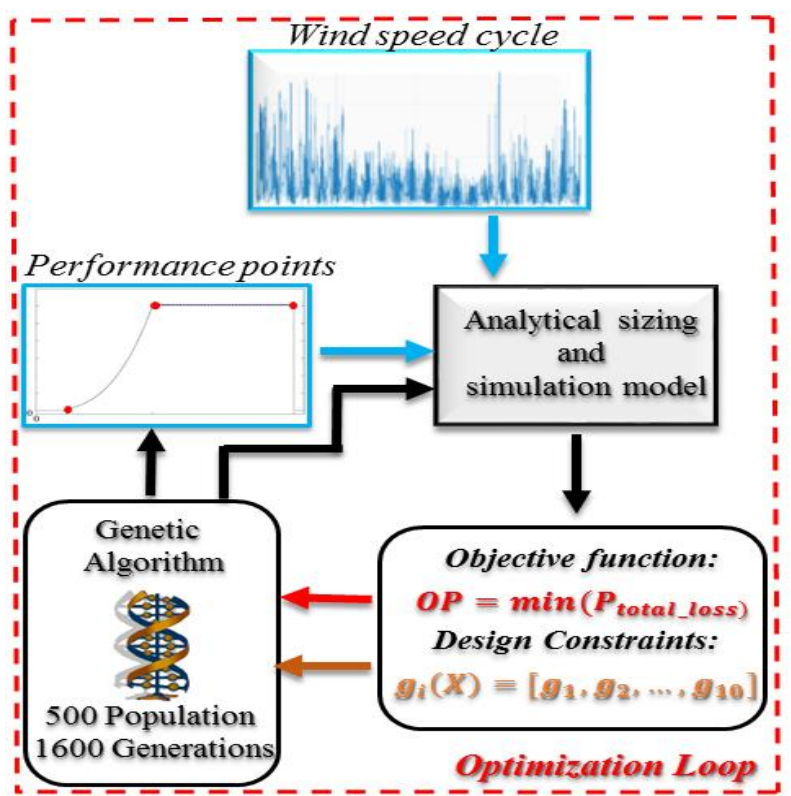

Fig. 5. Semi-analytical simulation model implementation in Matlab/Simulink environment

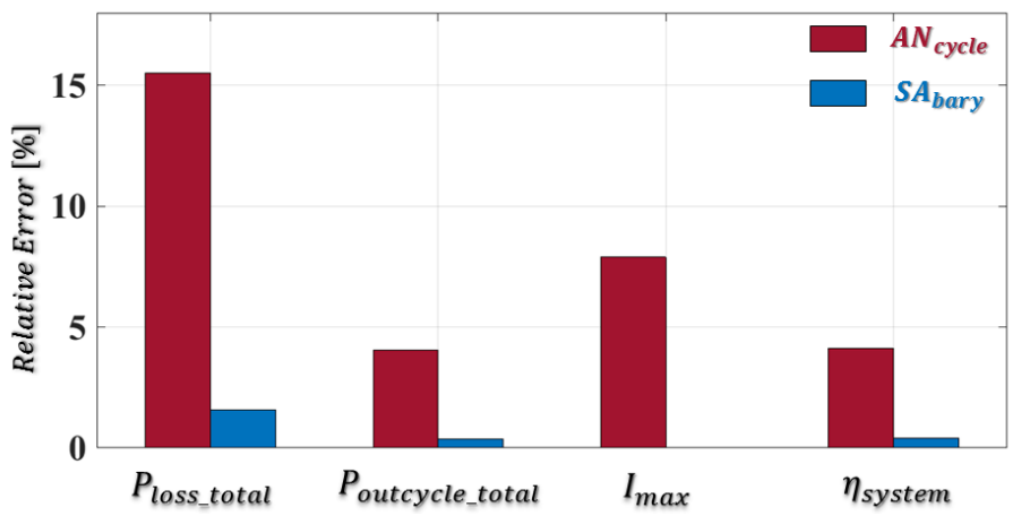

Fig. 6. Relative error between the analytical and semi-analytical models

Table 3. Analytical and semi-analytical models comparison

\begin{tabular}{cccc}
\hline \hline & $\begin{array}{c}\text { Analytic } \\
\text { with complete cycle }\end{array}$ & $\begin{array}{c}\text { Semi-analytic with } \\
\text { barycenter method }\end{array}$ & $\begin{array}{c}\text { Semi-analytic with } \\
\text { complete cycle }\end{array}$ \\
\hline \hline No. of operating points & 8,759 & 6 & 8,759 \\
\hline Simulation time & $<1[\mathrm{~s}]$ & $\approx 16[\mathrm{~s}]$ & $\approx 2[\mathrm{~h}]$ \\
\hline \hline
\end{tabular}

barycenter method. It is to be noted that the simulations of the semi-analytical model account for electrical dynamics, as they analyze the generator behavior during one electrical period $(0 \leq \mathrm{t} \leq \mathrm{T})$, but for mechanical steady-state, since only one wind speed value (i.e. the average wind speed over one hour wind speed measurements for the complete cycle and the wind speed value corresponding to the barycenter of one region for the barycenter method, respectively) is set as input for each simulation.

Previous work [6] established that just six regions are enough to partition the wind cycle and approximate, with an acceptable relative error, the total power losses in the wind energy system, as also noticeable in Fig. 6. The relative errors between the (i) analytical $\left(A N_{\text {cycle }}\right)$ model with complete cycle (red) and (ii) the semi-analytical $\left(S A_{\text {bary }}\right)$ model with barycenter method (blue), for several quantities, are provided. A comparison in terms of computation time and operating points is also given in Table 3.

\subsection{Two-level optimization approach}

For a refining of the optimization results with analytical model, a correction strategy that uses evaluations of the semi-analytical model associated to the barycenter method is proposed and implemented in the two level optimization approach, as presented in Fig. 7. As seen in the previous section, some differences arise between the output parameters of the analytical and semi-analytical models under complete cycle operation. 


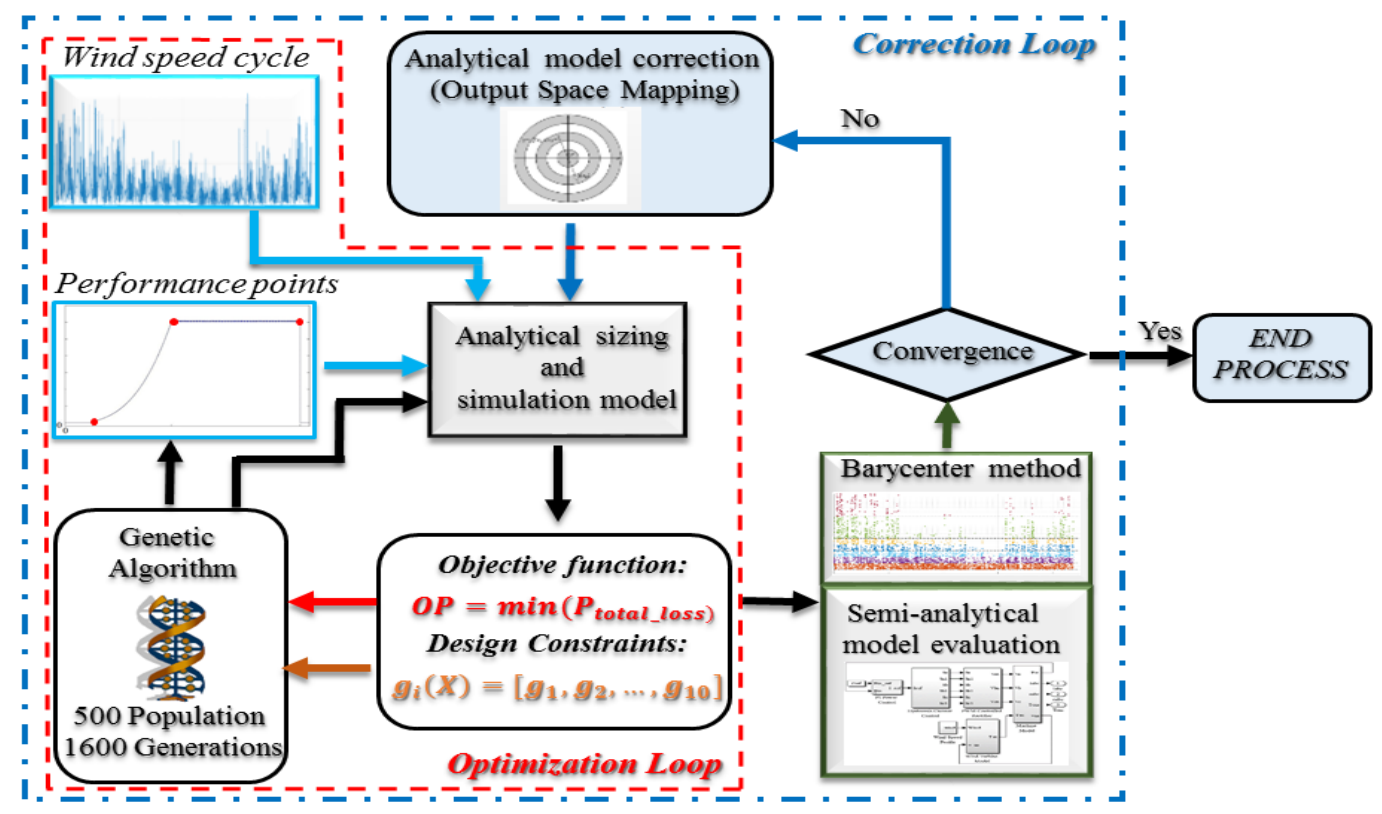

Fig. 7. Correction process of the analytical model by means of output space mapping

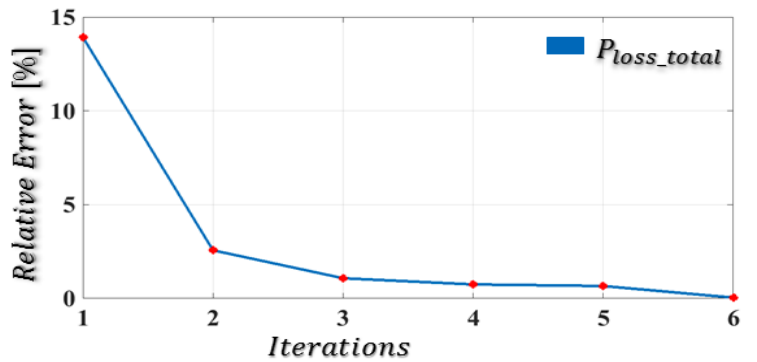

a)

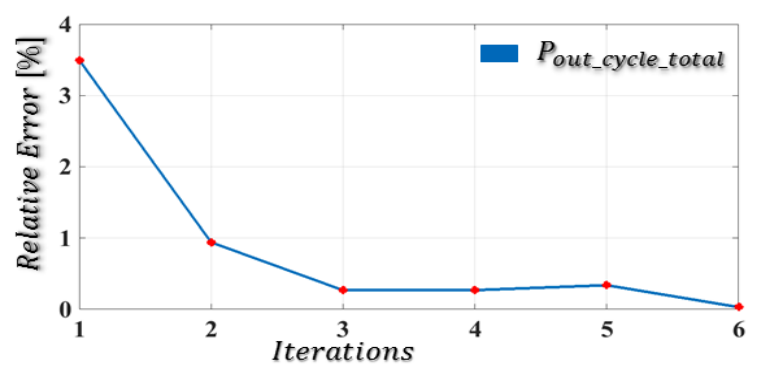

c)

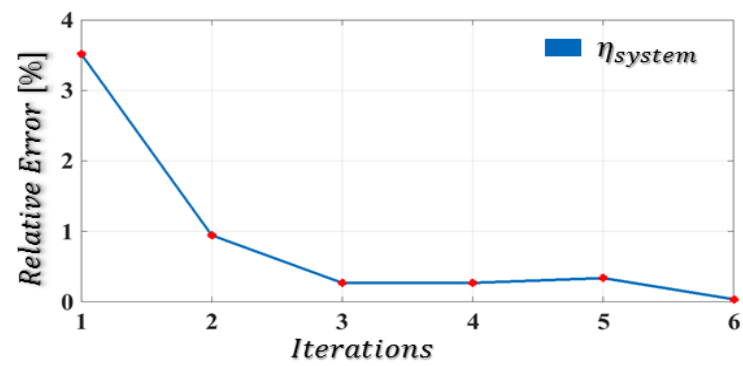

b)

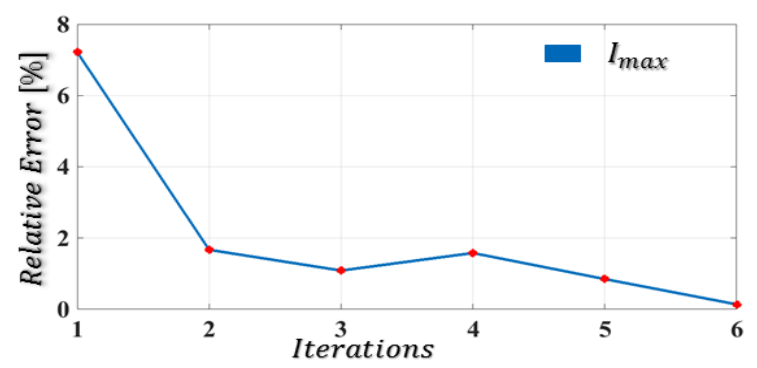

d)

Fig. 8. Convergence history for the a) total global losses in the wind turbine system, b) system efficiency, c) total output power over the wind cycle and d) maximum base current

This issue is fixed by building a surrogate model that includes the analytical model and a correction on its outputs. The optimization process is started again until the discrepancy between the surrogate (SU) model and the semianalytical model with barycenter method is small enough. The correction is based on output space-mapping technique [11].

The stop criterion of the correction loop (Fig. 7) is:

$$
100 \frac{\left|P_{\text {loss_total_SA }}^{k}-P_{\text {bary }}-P_{\text {loss_total_SU }}^{k}\right|}{\left|P_{\text {loss_total_SA }}^{k}\right|}<0.1 \%
$$

where the indexes $S A_{\text {bary }}$ and $S U$ correspond to the semi-analytical model associated to the barycenter method and surrogate model, respectively, while $k$ denotes the iteration. The convergence history for some particular output variables are displayed in Fig. 8. The optimal results found at the $6^{\text {th }}$ iteration were then used to compare the electromagnetic behavior of the BLDCPM generator with the semi-analytical model and finite element (FE) method. The cross-sectional model of the machine was thus created and subjected to transient magnetic field analysis by means of JMAG Designer software [12]. 


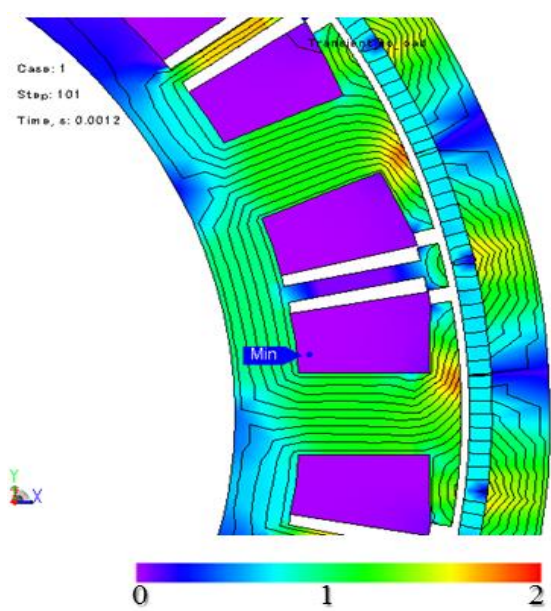

a)

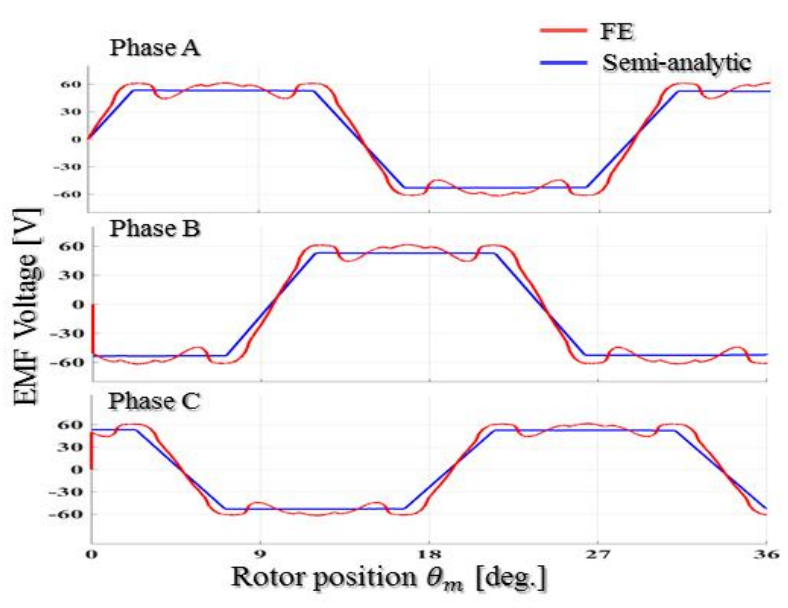

b)

Fig. 9. Magnetic flux-line distribution and flux density representation in FE (a) and comparative FE-computed and semianalytically-modeled back-EMF waveforms of the optimal BLDCPM generator (b)
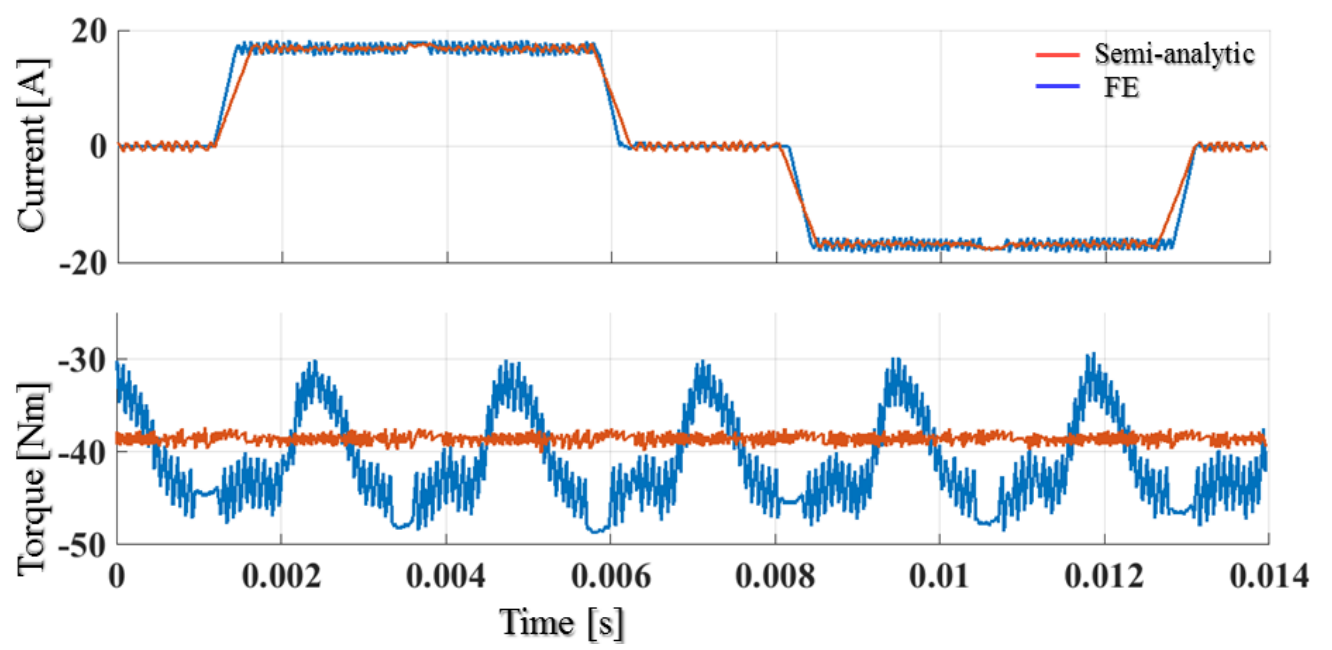

Fig. 10. FE and semi-analytically computed phase current and electromagnetic torque waveforms of the optimal BLDCPM generator

In Fig. 9 the magnetic flux density in the generator is shown, along with a comparison between the back-EMF waveforms, obtained through FE simulation under open-stator circuit (no-load) conditions and the ideal ones given by the semi-analytical model.

To visualize also the electromagnetic torque response of the generator and the stator-winding phase currents for the base operating point, a 2D FE time-stepping analysis was carried out, the obtained waveforms being displayed in Fig. 10 and compared to the ones given by the semi-analytical model. A dissimilarity can be noticed between the electromagnetic torque waveforms of the two models, as well as a relative error of $6 \%$ among their average values. This may be justified by the fact that neither the cogging torque (resulting from the interaction of the magnets with the slotted stator), nor the magnetic saturation have been considered in the semi-analytical model.

\section{Conclusions}

In this paper the optimal design of a direct-driven BLDCPM generator for use in micro-wind turbine applications has been investigated. The design optimization process is based on two simulation models, one more accurate and the other faster but not so precise and relies on the use of an evolutionary optimization algorithm to find the geometrical and electrical parameters that satisfy the problem constraints while performing the minimization of the power losses of the wind energy system over a long-term wind speed profile. For refined results, an adjustment of the analytical model based on output space-mapping has been implemented by comparison to the semi-analytical one associated to a barycenter method that allows easy exploitation of large amount of data available from the wind cycle. Comparative analysis have also been carried out through semi-analytical model and FE simulations for the optimal design of the BLDCPM generator found at the last iteration in the two level optimization approach. 


\section{Appendix}

\subsection{Wind Energy System Parameters}

The optimal design parameters (in bold) of the wind energy system found at the last iteration in the two level approach are listed below in Table 4, along with several other parameters considered fixed during the optimization process:

Table 4. Wind turbine system parameters

\begin{tabular}{|c|c|c|}
\hline System component & Parameter & Value \\
\hline \multirow{7}{*}{ Wind Turbine } & Radius of the turbine-rotor blades & $\mathrm{R}_{\mathrm{wt}}=1.5[\mathrm{~m}]$ \\
\hline & Friction coefficient & $\mathrm{f}_{\mathrm{wt}}=0.025[\mathrm{Nm} / \mathrm{rad}]$ \\
\hline & Optimal power coefficient & $\mathrm{C}_{\mathrm{p} \_o p t_{\mathrm{opt}}}=0.441$ \\
\hline & Optimal tip speed ratio & $\lambda_{\mathrm{opt}}=6.9$ \\
\hline & Cut-in wind speed & $v_{\text {in }}=2.9[\mathrm{~m} / \mathrm{s}]$ \\
\hline & Nominal wind speed & $\mathrm{v}_{\mathrm{n}}=9.77[\mathrm{~m} / \mathrm{s}]$ \\
\hline & Cut-off wind speed & $\mathrm{v}_{\max }=21.33[\mathrm{~m} / \mathrm{s}]$ \\
\hline \multirow[t]{27}{*}{ BLDCPM generator } & Number of pole pairs & $\mathbf{N}_{\mathrm{p}}=\mathbf{1 0}$ \\
\hline & Stator bore diameter & $D_{s}=216[\mathrm{~mm}]$ \\
\hline & Magnetic length & $\mathbf{L}_{\mathrm{m}}=76[\mathrm{~mm}]$ \\
\hline & Air gap thickness & $\mathrm{g}=1.1[\mathrm{~mm}]$ \\
\hline & Ratio length rotor/stator & $r_{r s}=1.128$ \\
\hline & Width of the main stator tooth & $\mathrm{l}_{\mathrm{th}}=12.47[\mathrm{~mm}]$ \\
\hline & Depth of the main stator tooth & $\mathrm{h}_{\mathrm{th}}=17.4[\mathrm{~mm}]$ \\
\hline & Total number of conductors & $\mathrm{n}=441$ \\
\hline & Thickness of the main stator pole shoe & $\mathrm{h}_{\mathrm{c}}=2.83[\mathrm{~mm}]$ \\
\hline & Width of the intermediate stator tooth & $l_{\text {th_int }}=2.5[\mathrm{~mm}]$ \\
\hline & Thickness of the intermediate stator pole shoe & $\mathrm{h}_{\mathrm{c}_{-} \text {int }}=2.88[\mathrm{~mm}]$ \\
\hline & Thickness of the permanent magnet & $\mathrm{h}_{\mathrm{pm}}=3[\mathrm{~mm}]$ \\
\hline & Thickness of the stator yoke & $\mathrm{h}_{\mathrm{sy}}=8.77[\mathrm{~mm}]$ \\
\hline & Thickness of the rotor yoke & $\mathrm{h}_{\mathrm{ry}}=7.8[\mathrm{~mm}]$ \\
\hline & Inner diameter & $\mathrm{D}_{\text {int }}=155[\mathrm{~mm}]$ \\
\hline & Outer diameter & $\mathrm{D}_{\text {ext }}=240[\mathrm{~mm}]$ \\
\hline & Peak magnetic induction in the airgap & $\widehat{\mathrm{B}}_{\mathrm{g}}=0.63[\mathrm{~T}]$ \\
\hline & Peak magnetic induction in the rotor yoke & $\widehat{\mathrm{B}}_{\mathrm{ry}}=1.52[\mathrm{~T}]$ \\
\hline & Peak magnetic induction in the stator yoke & $\widehat{B}_{\text {sy }}=1.22[\mathrm{~T}]$ \\
\hline & Peak magnetic induction in the stator teeth & $\widehat{\mathrm{B}}_{\mathrm{th}}=1.71[\mathrm{~T}]$ \\
\hline & Ratio DC voltage/EMF & $k_{v}=2.55$ \\
\hline & Current density & $\delta_{\text {dens }}=3.42\left[\mathrm{~A} / \mathrm{mm}^{2}\right]$ \\
\hline & Phase resistance & $\mathrm{R}_{\mathrm{ph}}=0.14[\mathrm{ohm}]$ \\
\hline & Phase inductance & $\mathrm{L}_{\mathrm{ph}}=3.7[\mathrm{mH}]$ \\
\hline & Base power & $\mathrm{P}_{\mathrm{b}}=1734[\mathrm{~W}]$ \\
\hline & Base speed & $\Omega_{\mathrm{b}}=45[\mathrm{rad} / \mathrm{s}]$ \\
\hline & Generator total mass & $\mathrm{M}_{\text {gen }_{-} \mathrm{t}}=14.7[\mathrm{~kg}]$ \\
\hline \multirow{2}{*}{ Three-phase rectifier } & Commutation frequency & $f_{s w}=25.8[\mathrm{kHz}]$ \\
\hline & DC bus voltage & $V_{d c}=263[V]$ \\
\hline
\end{tabular}




\section{References}

[1] B. Singh, S. Sharma, "PMBLDCG based stand-alone wind energy conversion system for small scale applications", International Journal of Engineering, Science and Technology, Vol. 4, No. 1, 2012, pp. 65-73A.

[2] G.-H. Rim R. Krishnan, "Modeling, simulation, and analysis of variable-speed constant frequency power conversion scheme with a permanent magnet brushless DC generator", IEEE Transactions on Industrial Electronics, Vol. 37, No. 4, 1990, pp. 291-296.

[3] J.F. Manwell, J.G. McGowan, A.L. Rogers, "Wind Energy Explained: Theory, Design and Application”, John Wiley \& Sons Publication, New York, USA, 2009.

[4] M. Belouda, A. Jaafar, B. Sareni, X. Roboam, J. Belhadj, "Design methodologies for sizing a battery bank devoted to a stand-alone and electronically passive wind turbine system", Renewable and Sustainable Energy Reviews, Elsevier, Vol. 60, 2016, pp. 144-154.

[5] S. Brisset, P. Brochet, "Analytical model for the optimal design of a brushless DC wheel motor", COMPEL, Vol. 24, No. 3, 2005, pp. 829-848.

[6] A. Laczko, S. Brisset and M.M. Radulescu, "Modeling approaches to brushless DC permanent-magnet generator for use in micro-wind turbine applications," International Conference on Electrical Machines (ICEM), IEEE, 2016, pp. 445-451.

[7] A. Laczko, M.V. Zaharia, M.M. Radulescu, S. Brisset, "Modeling and simulation of a brushless DC permanent-magnet generator-based wind energy conversion system", International Conference on Ecological Vehicles and Renewable Energies (EVER), IEEE, 2015, pp. 1-7.

[8] P. Andrada, M. Torrent, J.L. Perat, B. Blanque, B., "Power Losses in Outside-Spin Brushless D.C. Motors", Renewable Energy and Power Quality Journal, Vol. 1, No. 2, April 2004, pp. 507-511.

[9] Texas Instruments, “230-V, 250-W, High Efficiency BLDC Motor Drive with DC-Bus Voltage Ripple Compensation”, Application report.

[10] D. E. Golberg, "Genetic algorithms in search, optimization, and machine learning", Addion Wesley, Boston, USA, 1989, p. 102.

[11] M. H. Bakr, J. W. Bandler, “An Introduction to the Space Mapping Technique”, Optimization and Engineering, Vol. 2, 2001, pp. 369-384.

[12] www.jmag-international.com. 